\title{
EPIDEMIOLOGICAL PROFILE OF PATIENTS WITH PROXIMAL HUMERUS FRACTURE TREATED AT HOSPITAL SÃO PAULO, BRAZIL
}

\author{
ana Paula Cortes de Oliveira ${ }^{1}$, Mariana Christovam Mestierl ${ }^{1}$, José Carlos Baldocchi Pontin $^{1}$
}

\section{ABSTRACT}

Objective: To analyze the epidemiological aspects of proximal humerus fractures and describe the profile of patients with proximal humerus fractures hospitalized and treated at Hospital São Paulo, between 2008 and 2013. Methods: Hospital records were retrospectively analyzed for surgically treated patients diagnosed with proximal humerus fracture. Age, gender, injury mechanism, length of hospital stay, performed treatment and associated diseases were considered. Results: From all patients studied, 52 were female at their sixth decade of life.
As for the injury mechanism, fall from height was the main cause for women (88.46\%) and for man it was motorcycle accidents (31.42\%). Fixation with locked plate was the most frequently used treatment. Conclusion: Most patients were female in their fifth decade of life, injured mainly by fall from height. Fixation with locked plate was the most frequently used treatment and the patients were admitted for 7 days, on average. Level of Evidence II, Retrospective Study.

Keywords: Humeral fractures. Shoulder fractures. Epidemiology.

Citation: Oliveira APC, Mestieri MC, Pontin JCB. Epidemiological profile of patients with proximal humerus fracture treated at Hospital São Paulo, Brazil. Acta Ortop Bras. [online]. 2015;23(5):271-4. Available from URL: http://www.scielo.br/aob.

\section{INTRODUCTION}

Epidemiological studies classify humeral fracture the seventh most common in the human body, and fracture of the proximal portion corresponds to about $80 \%$ of the humerus fractures. Its incidence is 63-73 cases per 100.000 inhabitants, predominantly in the elderly. It is estimated that about $80 \%$ of individuals with this type of fracture are over 60 years old and it is more common in females, by a ratio of three women to every man. ${ }^{1-6}$ The main mechanisms of injury for this type of fracture are falls from height over the outstretched hand with the elbow to the ground in external rotation associated with shoulder abduction, or by direct trauma on the lateral side of the shoulder. ${ }^{6-8}$

Some studies have shown that besides low bone density, other factors such as low levels of physical activity, decreased visual acuity and history of previous falls justify the high occurrence in the elderly. ${ }^{9}$ In younger patients, the proximal humerus fractures have distinct epidemiological and clinical characteristics, and are usually caused by high-energy trauma, such as traffic accidents. ${ }^{10,11}$

Conservative treatment, consisting of immobilization with simple sling is indicated by up to $85 \%$ of cases resulting from lowenergy trauma, since they have little deviation between the fragments, i.e., up to $1 \mathrm{~cm}$ or $45^{\circ}$ according to Neer's classification criteria..$^{5,6,9}$

Surgical treatment is indicated for unstable fractures with rotational deformity that are difficult to reduce and maintain. ${ }^{2,4}$ Among the most common procedures, fixation with plates and screws, percutaneous fixation with wires, tension band, external fixation, fixed-angle plates, blocked plates and arthroplasty stand out. Arthroplasty is usually performed on patients with extensive involvement are the articulating cartilage, in case of avascular necrosis or in elderly patients with complex fractures that are difficult to fixate, due to osteoporosis., 4,12,13

Given the scarcity of epidemiological studies in Brazil, it is essential to survey and map the characteristics of individuals who have suffered proximal humerus fractures, as well as the impact of this clinical condition to health services, aimed at making better decision by professionals regarding assistance, preventive measures and reducing comorbidities and mortality. Thus, the objectives of this study are to analyze the profile of patients with proximal humerus fractures hospitalized and treated at Hospital São Paulo, São Paulo, SP, Brazil, and verify the average length of hospital stay, comorbidities and treatment performed.

All the authors declare that there is no potential conflict of interest referring to this article.

\begin{abstract}
1. Universidade Federal de São Paulo, Escola Paulista de Medicina, Department of Orthopedics and Traumatology, Physiatry Discipline, São Paulo, SP, Brazil.
\end{abstract}
Work developed at Universidade Federal de São Paulo, Escola Paulista de Medicina, Department of Orthopedics and Traumatology, Physiatry Discipline, São Paulo, SP, Brazil. Correspondence: José Carlos Baldocchi Pontin. Departamento de Ortopedia e Traumatologia - UNIFESP. Rua Napoleão de Barros, 715, 10 andar, Vila Clementino. 04024-002. São Paulo, SP, Brazil. zeca.fisio13@hotmail.com 


\section{METHODS}

This is a retrospective study of medical records of patients with proximal humerus fractures treated surgically at Hospital São Paulo, São Paulo, SP, Brazil, from 2008 to 2013. Exclusion criteria were considered patients who underwent conservative treatment, patients who were transferred to other services, or those who had incomplete records.

After detailed analysis of the records, 90 cases of proximal humerus fractures were identified. Three of these records were from patients who were treated by non-surgical methods and were, thus, excluded from this study. Parameters evaluated were: gender, age, trauma mechanism, associated diseases, length of stay and type of surgery performed.

Information in the database were stored and analyzed by an Excel 2010 software and a descriptive analysis of the data was conducted. Data were presented through percentages and averages.

This study was approved by the Ethics Research Committee of Universidade Federal de São Paulo, UNIFESP, São Paulo, Brazil, with under $N^{\circ} 385,618$ and Resolution $N^{\circ}$ 18261713.4.0000.5505.

\section{RESULTS}

This research traced the profile of 87 patients with proximal humerus fractures treated at Hospital São Paulo. There was female predominance in the sample $(59.77 \%)$ compared to males (40.23\%). The mean age was 65 years old for women and 47 years old for men. (Table 1 )

The analysis by age group showed a higher incidence of fractures in men between 30 and 39 years old and women aged between 60 and 69 years. (Figure 1)

Considering the mechanism of injury among women, most were low energy trauma, being $88.46 \%$ fall to the ground,

\begin{tabular}{c|c|c|c|c|c}
\multicolumn{2}{c}{ Table 1. Sample distribution by gender and age. } \\
\hline & & & \multicolumn{3}{|c}{ Age (years old) } \\
\hline Gender & N & $\%$ & Mean & Minimum & Maximum \\
\hline Feminine & 52 & $59.77 \%$ & 65.26 & 17 & 88 \\
\hline Masculine & 35 & $40.23 \%$ & 47.45 & 22 & 82 \\
\hline Total & 87 & $100 \%$ & 58.10 & 19.5 & 85 \\
\hline
\end{tabular}

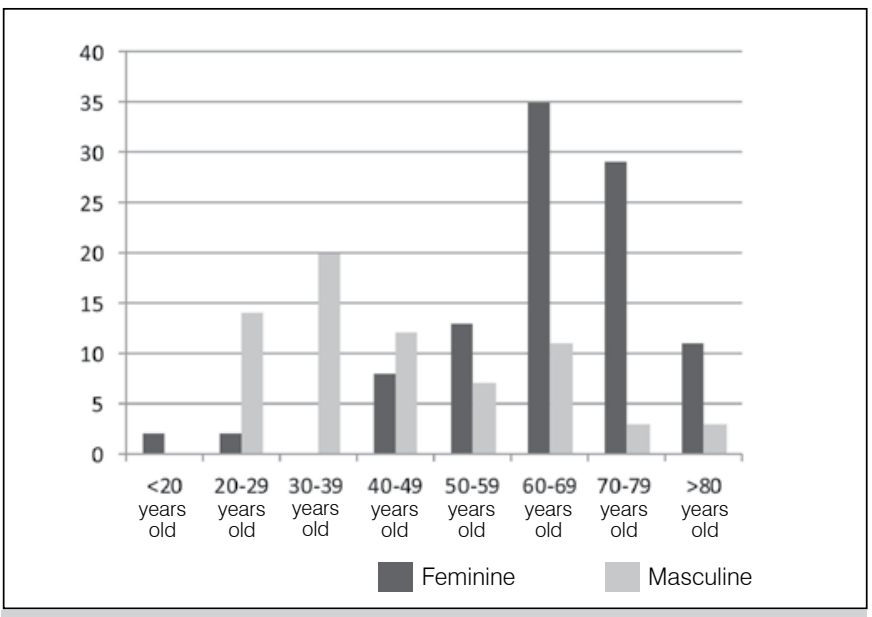

Figure 1. Distribution of gender by age range. while among men the most common mechanism of injury was motorcycle accident (31.42\%), followed by fall to the ground (25.71\%). (Table 2)

Among previous diseases reported by the patients, systemic hypertension showed higher prevalence, followed by diabetes mellitus, osteoporosis, osteoarthritis, high cholesterol and HIV. (Figure 2)

Regarding the surgical treatment of fractures in women, the most frequent were locked plate (53\%), total arthroplasty (21\%), locked intramedullary nail (19\%), and partial arthroplasty (5\%). Among men, the most frequent were locked plate (82\%), locked intramedullary nail (8\%), pinning (2\%), total arthroplasty (2\%) and partial arthroplasty (2\%). (Table 3 ) The average length of hospital stay was 7 days (range 1-23 days). (Table 4)

Table 2. Distribution by gender, showing trauma mechanisms.

\begin{tabular}{c|c|c|c|c}
\hline & Fem & $\%$ & Masc & $\%$ \\
\hline Automobile accident & 1 & $1.92 \%$ & 0 & $0.00 \%$ \\
\hline Running over & 4 & $7.69 \%$ & 5 & $14.28 \%$ \\
\hline Fall to the ground & 46 & $88.46 \%$ & 9 & $25.71 \%$ \\
\hline Fall from stairs & 1 & $1.92 \%$ & 2 & $5.71 \%$ \\
\hline Motorcycle accident & 0 & $0.00 \%$ & 11 & $31.42 \%$ \\
\hline Fall from height & 0 & $0.00 \%$ & 6 & $17.14 \%$ \\
\hline Physical assault & 0 & $0.00 \%$ & 1 & $2.85 \%$ \\
\hline Pathological fracture & 0 & $0.00 \%$ & 1 & $2.85 \%$ \\
\hline Total & 52 & $100.00 \%$ & 35 & $100.00 \%$ \\
\hline
\end{tabular}

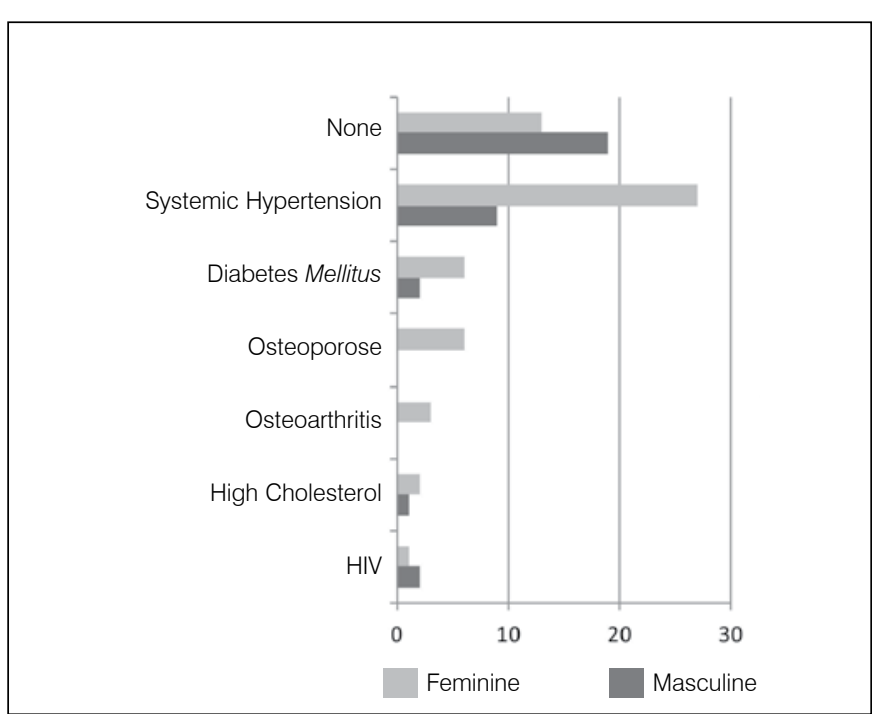

Figure 2. Distribution by gender of associated diseases.

Table 3. Distribution by gender of treatment performed.

\begin{tabular}{c|c|c|c|c}
\hline & Fem & $\%$ & Masc & $\%$ \\
\hline Total arthroplasty & 11 & $21.15 \%$ & 1 & $2.85 \%$ \\
\hline Partial arthroplasty & 3 & $5.76 \%$ & 1 & $2.85 \%$ \\
\hline Intramedullary nail & 10 & $19.23 \%$ & 3 & $8.57 \%$ \\
\hline Locked plate & 28 & $53.84 \%$ & 29 & $82.85 \%$ \\
\hline Pinning & 0 & $0.00 \%$ & 1 & $2.85 \%$ \\
\hline Total & 52 & $100.00 \%$ & 35 & $100.00 \%$ \\
\hline
\end{tabular}


Table 4. Days of hospital stay.

\begin{tabular}{c|c|c|c|c|c}
\hline \multicolumn{5}{c}{ Mean distribution of hospital stay according to gender. } \\
\hline & & & \multicolumn{3}{|c}{ Time (days) } \\
\hline Gender & N & $\%$ & Mean & Minimum & Maximum \\
\hline Feminine & 52 & $59.77 \%$ & 7.9 & 1 & 23 \\
\hline Masculine & 35 & $40.23 \%$ & 7.58 & 1 & 21 \\
\hline Total & 87 & $100 \%$ & 7.74 & 1 & 22 \\
\hline
\end{tabular}

\section{DISCUSSION}

Presently, there is no epidemiological study of humeral proximal fractures in the national literature. Therefore, this study becomes relevant, especially if we take into account the socio-economic impact involved in the genesis of this and other traumatic injuries caused by domestic accidents (in the elderly) and traffic accidents involving motorcycles (in young adults), since the morbidity associated with this type of injury is significant, with functional disability ranging on average 2-3 months. . $^{8,14}$

Several aspects were analyzed in order to characterize the profile of patients with these diagnoses treated at Hospital São Paulo. In addition, the data corresponding to the various types of treatment proposed, length of stay and associated diseases were also analyzed.

In this study there was a predominance of females over males ( $59.77 \%$ vs. $40.23 \%$ ), data that corroborates the study by Kim et al. ${ }^{15}$ in 2008, in which a survey was made of data from patients seen at the emergency department with proximal humerus fractures diagnoses. From 180,300 cases, 128,200 (70\%) were female patients, while 56,100 (30\%) were male. A similar result was also found in the review by Court-Brown and Caesar $^{16}$ in 2006 with 337 patients with proximal humerus fracture included in the study, $70 \%$ of the feminine gender. ${ }^{15,16}$

The mean age of patients included in this study was 65.2 years old for women and 47.4 years old for men. These data corroborate the findings of Kim et al., ${ }^{15}$ who found in their study an increase in the prevalence of this type of fracture with increasing age in both genders. Compared to women aged between 40-44 years old, the risk of proximal humerus fractures increased fivefold in the age group of 60-64 years old and 21 times in the age group of 80-84 years old, a fact explained by associated osteoporosis.

The sample in the study by Court, Brown and Caesar ${ }^{16}$ was 64.8 years old on average, and most of the sample consisted of individuals aged between 50 and 65 years, as in the present study's sample.

Palvanen et al., ${ }^{7}$ in an epidemiological study conducted in Finland, found that the mean age was 78 years old for women and 73 years old for men. The longer survival rate in women causes the number of elderly women to be higher, increasing the risk factors for these fractures. These data corroborate those of the present study, which also found the a higher mean age for women, however the mean age in the Finnish study was much higher.

The most common mechanism of injury among women in this study was to fall from height (88.46\%), and among men Acta Ortop Bras. 2015;23(5):271-4 it was motorcycle accident (31.42\%). Data from this study corroborates the study by Schwartz et al. ${ }^{20}$ and the study of Kim et al., ${ }^{15}$ who reported that $88 \%$ of humeral fractures are caused by fall from height, followed by traffic accidents (8\%). Most fractures occurred as a result from fall and direct impact on the fracture site (proximal humerus), which reinforces the idea that the etiology of this type of fracture is predominantly osteoporotic. . $^{8,14}$

In our study, a small part of the population had osteoporosis as an associated disease, but this finding should be interpreted with caution, since health policies in the country are deficient and much of the population do not know they have the disease. A number of strategies have been implemented in the US health programs for the prevention of falls among the elderly. Among them, making home a safer environment by eliminating the risk factors, increasing physical activity, installing more lights making the environment less dark, use of walking aid devices, wearing comfortable shoes, among others. A clinical trial showed that a multifactorial prevention program reduces in fact the incidence of falls in the elderly. ${ }^{17,18}$

We can observe that, among men, the most common mechanism of injury was motorcycle accident. Early last decade, between 20 and 50 million people around the world became totally or partially incapacitated due to injuries caused by traffic accidents and about $10 \%$ occupied hospital beds during this period. The high incidence of fractures among men arising from this type of accident draws attention to the need for prevention policies and traffic education. ${ }^{19}$

Recent government campaigns to warn people about the consumption of alcoholic beverages, as well as the increased supervision and punishment in case of violation of traffic laws aim to reduce the number of accidents and deaths on the streets and roads of Brazil. Moreover, in medium to long term, it is believed that the mass of enforcement and education measures can change this epidemiological paradigm that exists in Brazil. ${ }^{20}$

In the present study, the most frequent surgical treatment fracture was fixation with locked plate $(53.84 \%$ of women and $82.85 \%$ of men). Among women it was observed that, after fixation with plates, total arthroplasty was the most common procedure. This may be due to poor bone quality among osteoporotic women, which disrupts bone healing and may have a high chance of breakage and loosening of the implant. Treatment varies according to the type of fracture, and generally clean line fractures without deviation are treated conservatively with cast immobilization. The study by Checchia et al. ${ }^{11}$ suggests that conservative treatment is indicated by up to $85 \%$ of cases, since it is a result of low energy trauma and exhibit little deviation from fragment. ${ }^{11,21}$

There is no consensus in the literature regarding the best surgical treatment method for proximal humerus fractures and the experience with a particular technique employed by a certain group may not be reproducible in other centers. It is known that the use of plates and screws allows good fixation in bones with good quality, but it is not uncommon loosening of the synthesis material in bones with poor quality due to insufficient screw fixation, plus the ability to cause subacromial impingement syndrome by migration of the screws. ${ }^{22,23}$ 


\section{CONCLUSION}

It was observed in the population studied that most patients suffering proximal humerus fracture are predominantly female elderly victims who fell to the ground. Among male patients, the most common mechanisms of injury are traffic accidents. Most of the population served presented hypertension as prior comorbidity. The surgery most frequently performed was placement of locked plate; patients remained in hospital on average for 7 days. It is, then, suggested that preventive measures such as the prevention of osteoporosis and falls in older adults must be urgently taken to reduce the occurrence of fractures related to aging.

It also requires more government investment regarding control measures and traffic education to reduce the accident rate.

\section{REFERENCES}

1. Smith LK, Weiss El, Lehmkukl LD. Bunnstrom's clinical kinesiology. 5th ed. Philadelphia: FA Davis; 1996.

2. Netter FH. Atlas de anatomia humana. 2ª . Ed. Porto Alegre: Artmed; 1997.

3. Checchia SL, Miranda DL, Carneiro UM, Cassani R. Tratamento das fraturas do colo cirúrgico do úmero pela técnica de Kapandji. Rev Bras Ortop. 1993;28(1/2):43-9;

4. Morelli SS, Travizanuto SE. Fraturas da extremidade proximal do úmero; estudo comparativo entre dois métodos de fixação. Acta Ortop Bras. 2010;18(2):79-84.

5. Court-Brown CM, Caesar B. Epidemiology of adult fractures: A review. Injury. 2006;37(8):691-7

6. Lind T, Kroner K, Jesen J. Epidemiology of fractures of the proximal humerus. Arch Orthop Trauma Surg. 1989;108(5):285-7.

7. Palvanen M, Kannus $P$, Niemi S, Parkkri J. Update in the epidemiology of proximal humeral fractures. Clin Orthop Relat Res. 2006;(442):87-92.

8. Lee SH, Dargent-Molina P, Bréart G; EPIDOS Group. Epidemiologie de I'Osteoporose Study. Risk factors for fractures of the proximal humerus: results from the EPIDOS prospective study. J Bone Miner Res. 2002;17(5):817-25.

9. Barbosa RI, Marcolino AM, Fonseca MC, Mazzer N, Zatiti SC. Avaliação retrospectiva de pacientes com fratura proximal de úmero fixada com placa com parafusos de ângulo fixo para região proximal do úmero. Acta Ortop Bras. 2008;16(2):89-92.

10. Wijgman AJ, Roolker W, Patt TW, Raaymakers EL, Marti RK. Open reductionand internal fixation of three and four-part fractures of the proximal part of the humerus. J Bone Joint Surg Am. 2002;84(11):1919-25.

11. Checchia SL, Doneux Santos $P$, Miyazaki NA, Fregoneze M, Silva LA, Lobo A, et al. Avaliação do tratamento cirúrgico do úmero com placa pfs 80 . Rev Bras Ortop. 2004;39(10):555-67

12. Basti JJ, Dionysian E, Sherman PW, Bigliani LU. Management of proximal humeral fractures. J Hand Ther. 1994;7(2):111-21.
13. Neer CS 2nd. Articular replacement of the humeral head. J Bone Joint Surg Am. 1955;37(2):215-28.

14. Greenspan SL, Myers ER, Maitland LA, Resnick NM, Hayes WC. Fall severity and bone mineral density as risk factors for hip fracture in ambulatory elderly. JAMA. 1994;271(2):128-33.

15. Kim SH, Szabo RM, Marder RA. Epidemiology of humerus fractures in the United States: nationwide emergency department sample, 2008. Arthritis Care Res (Hoboken). 2012;64(3):407-14.

16. Court-Brown CM, Caesar B. Epidemiology of adult fractures: a review. Injury. 2006;37(8):691-7.

17. Schwartz AV, Nevitt MC, Brown BW Jr, Kelsey JL. Increased falling as a risk factor for fracture among older women: the study of osteoporotic fractures. Am J Epidemiol. 2005;161(2):180-5.

18. Jensen J, Lundin-Olsson L, Nyberg L, Gustafson Y. Fall and injury prevention in older people living in residential care facilities. A cluster randomized trial. Ann Intern Med. 2002;136(10):733-41.

19. Souza ER, Minayo MC, Franco LG. Avaliação do processo de implantação e implementação do Programa de Redução da Morbimortalidade por Acidentes de Trânsito. Epidemiol Serv Saúde. 2007;16(1):19-31.

20. Albuquerque RP, Hara R, Prado J, Schiavo L, Giordano V, Amaral NP. Estudo epidemiológico das fraturas do planalto tibial em Hospital de Trauma nível I. Acta Ortop Bras. 2013;21(2):109-15.

21. Handoll HH, Ollivere BJ, Rollins KE. Interventions for treating proximal humeral fractures in adults. Cochrane Database Syst Rev. 2012;12:CD000434.

22. Helmy N, Hintermann B. New trends in the treatment of proximal humerus fractures. Clin Orthop Relat Res. 2006;(442):100-8.

23. Koukakis A, Apostolou CD, Taneja T, Korres DS, Amini A. Fixation of proximal humerus fractures using the PHILOS plate: early experience. Clin Orthop Relat Res. 2006;(442):115-20. 